\title{
GIẢNG DẠY VÀ HỌC TẬP DỰA TRÊN CÁC PHƯƠNG PHÁP HỌC TẬP CHỦ ĐộNG VÀ TRẢI NGHIỆM - HỌC PHẦN THỰC HÀNH XÂY DỰNG Hệ THỐNG QUẢN LÝ MÔI TRƯờnG ISO 14001:2015
}

\author{
Nguyễn Thị Xuân Hạnh ${ }^{(*)}$, Bùi Phạm Phương Thanh ${ }^{(*)}$ \\ (*) Thạc sĩ. Truò̀ng Đại học Thủ Dầu Một.Email: hanhntx@tdmu.edu.vn
}

DOI: $10.37550 /$ tdmu.CFR/2021.01.121

\section{Tóm tắt}

Đề xuớng CDIO: C (Conceive): Hình thành ý tương, D (Design): Thiết kế, I (Implement): triển khai, O (Operate): vận hành. Ở tiêu chuẩn 8 - Học tập chủ động và trải nghiệm, với tinh thần của tiêu chuẩn này, nhóm tác giả thực hiện bài viết ứng dụng tiêu chuẩn 8 vào hoc phần xây dụng hệ thống quản lý môi truòng - ISO 14001có tính chất thưc hành nhằm phân tích cách thức thực hiện tiêu chuẩn theo tinh thần của đề xuớng. Trong hoc phần thưc hành, Giảng viên huớng dẫn sinh viên học tập chủ động bằng cách giao cho sinh viên chọn lụa một địa điểm mà sinh viên dễ dàng tiếp cận thực hiện phân tích các điều khoản và xây dưng hệ thống. Đối với tiêu chuẩn quốc tế ISO 14001 thì việc hiểu tiêu chuẩn đã khó, tiếp cận một đơn vị để ưng dụng việc hiểu của minh còn khó hơn. Với việc xây dưng được hệ thống quản lý môi truờng, buộc sinh viên phải được tiếp cận gần nhất với đơn vị, được đơn vị tiếp nhận và tạo điều kiện quan sát làm bài. Việc giảng viên cho sinh viên lựa chọn bất kỳ đơn vị nào, và khuyến khích sinh viên chọn các đơn vị là nhũng nơi sinh viên đang làm thêm, nơi quen biết để sinh viên có nhiều điều kiện để quan sát và thưc hành.

Tù khóa: tiêu chuẩn 8 - CDIO, tiêu chuẩn ISO 14001, các điều khoản, học tập chủ động và trải nghiệm, hoc phần thưc hành

\section{1. Đặt vấn đề}

Học tập chủ động là hoạt động cho phép sinh viên tham gia vào các quá trình học tập trong bài giảng để giảng viên và sinh viên có thể xác định được sự thành thạo kiến thức và điều chỉnh các hướng dẫn để tạo điều kiện cho học tập lâu dài. Trong bài viết này, tác giả áp dụng tiêu chuẩn 8 học tập chủ động và trải nghiệm theo đề xướng CDIO hướng dẫn sinh viên học tập chủ động ở học phần thực hành. Việc áp dụng tiêu chuẩn 8 vào học phần này cũng thuận lợi cho giảng viên triển khai các nội dung môn học, bên cạnh nâng cao các kỹ năng xã hội, khả năng quan sát thực tế và suy luận, bên cạnh tư duy logic cho sinh viên. 
Bài viết này tác giả nêu các bước và cách thức triển khai học tập chủ động và trải nghiệm, những thuận lợi và khó khăn khi áp dụng vào thực tế giảng dạy học phần tiêu chuẩn Quốc tế ISO 14001. Đối với học phần này, việc giảng dạy bằng trình chiếu, bằng thuyết giảng trong lớp sẽ không là lựa chọn tốt nhất, nếu không nói là không phù hợp. Việc thực hành sinh viên cần có môi trường cụ thể để tập tành ứng dụng và khám phá. Tuy nhiên phần lý thuyết triển khai đã có một học phần lý thuyết trước để sinh viên làm quen với các điều khoản tiêu chuẩn, với bối cảnh ra đời, với cách thức ứng dụng vào thực tế. Trong học phần lý thuyết này, giảng viên đã chuẩn bị sẵn và đưa ra một mô hình chung để sinh viên làm quen với việc áp dụng, để sinh viên phân tích và khi bước qua học phần thực hành, sinh viên sẽ bớt bỡ ngỡ và dễ dàng nắm bắt vấn đề hơn.

\section{Nội dung}

\subsection{Bối cảnh của học phần thục hành}

Học phần xây dựng hệ thống quản lý môi trường - ISO 14001 là học phần theo tiêu chuẩn Quốc Tế. Đây là tiêu chuẩn Quốc Tế được Việt Nam công nhận thành tiêu chuẩn Việt Nam và được lưu hành đến nay trải qua 3 phiên bản 1996, 2004 và 2015. [4]. Vì thế các điều khoản trong tiêu chuẩn này với những thuật ngữ được sử dụng chung cho các quốc gia trên thế giới. Tiêu chuẩn Việt Nam ISO14001:2015 viết tắt là: TCVN ISO 14001:2015 mục đích hình thành là để tạo ra một chuẩn chung về hệ thống quản lý môi trường cho các quốc gia trên Thế giới. Chúng ta hiểu là để gia nhập vào sân chơi chung của Thế giới chúng ta phải vào một mạng lưới tương đồng với nhau về các thỏa thuận, cam kết. Ở Việt Nam, tiêu chuẩn này là tự nguyện tham gia nếu các công ty, tổ chức, doanh nghiệp nào cảm thấy cần thiết, việc tham gia vào ngoài mục đích khẳng định trách nhiệm của đơn vị mình với môi trường, tìm kiếm các hợp đồng các đối tác làm ăn trên thế giới có trách nhiệm với môi trường, thì còn đảm bảo cho doanh nghiệp đó tuân thủ luật bảo vệ môi trường Việt Nam. Tuy nhiên theo luật bảo vệ môi trường năm 2013 [5] thì ở phụ lục II, có 14 nhóm ngành nghề phát thải lớn, gây ô nhiễm nặng như: Dệt nhuộm, thuộc da, hóa chất, xi mạ, chất thải rắn, nước thải... sẽ phải bắt buộc xây dựng hệ thống môi trường của Việt Nam. Chính vì thế việc giảng dạy và thực hành tiêu chuẩn này sẽ giúp cho sinh viên có cơ hội ra trường tìm việc và luật bảo vệ môi trường như là một bảo hộ công việc cho sinh viên theo hướng tiêu chuẩn Quốc tế sau này.

Học phần thực hành nên sinh viên buộc phải ra ngoài thực hành, vì thế môi trường để sinh viên thực hành bên ngoài là rất quan trọng. Đối với tiêu chuẩn quốc tế này thì tìm được môi trường thực hành bên ngoài là rất khó và phải nói là rất ít cơ hội sinh viên được nhận vào công ty, xí nghiệp để tìm hiểu và làm bài theo dạng này. Chính vì thế, việc nghĩ ra cách thức để sinh viên tiếp cận học tập thực hành là rất cấp thiết. Đối với học phần này nếu không tìm được nơi thực tế để học tập thì gần như khi triển khai học sinh viên rất khó khăn để hiểu vấn đề.

\subsection{Triển khai bài giảng}

Việc triển khai học phần thực hành xây dựng hệ thống quản lý môi trường phải theo cách thức học tập chủ động của CDIO phải bám sát theo các điều khoản của tiêu chuẩn ISO 14001. Trong ISO 14001 có 10 điều khoản, tuy nhiên khi thực hiện giảng dạy thì giảng viên 
sẽ phổ biến các điều khoản mà sinh viên có khả năng tiếp cận, và phù hợp với logic điều khoản. Sau đây là bảng liệt kê 10 điều khoản tiêu chuẩn ISO 14001.

Bảng 1. Các điều khoản tiêu chuẩn ISO 14001

\begin{tabular}{|l|l|l|}
\hline Stt & Số điều khoản & Tên điều khoản \\
\hline 1 & Điều khoản 1 & Phạm vi áp dụng \\
\hline 2 & Điều khoản 2 & Tài liệu viện dẫn \\
\hline 3 & Điều khoản 3 & Thuật ngữ, định nghĩa \\
\hline 4 & Điều khoản 4 & Bối cảnh của tổ chức \\
\hline 5 & Điều khoản 5 & Sự lãnh đạo \\
\hline 6 & Điều khoản 6 & Hoạch định \\
\hline 7 & Điều khoản 7 & Hỗ trợ \\
\hline 8 & Điều khoản 8 & Thực hiện \\
\hline 9 & Điều khoản 9 & Đánh giá kết quả hoạt động \\
\hline 10 & Điều khoản 10 & Cải tiến \\
\hline
\end{tabular}

Nguồn: TCVN ISO 14001:2015 - Hà Nội 2015

Trong bảng này, giảng viên chỉ có thể triển khai một số điều khoản để sinh viên học tập. Các điều khoản được triển khai giảng dạy là điều khoản hạt nhân quan trọng nhất của tiêu chuẩn ISO14001. Các điều khoản chưa triển khai trên lớp sẽ là các điều khoản sinh viên khó có khả năng tiếp cận nếu không phải là nhân viên trong công ty, xí nghiệp, và không phụ trách mảng môi trường hoặc có vị trí có thể tiếp cận tài liệu quan trọng của công ty.

Bảng 2. Các điều khoản trong ISO 14001 giảng viên triển khai trong giảng dạy

\begin{tabular}{|c|c|c|c|}
\hline Stt & Số điều khoản & Tên điều khoản & Cách thức triển khai \\
\hline 1 & Điều khoản 1 & $\begin{array}{l}\text { Phạm vi áp } \\
\text { dụng }\end{array}$ & $\begin{array}{l}\text { Xác định vị trí, địa chỉ của tổ chức, xác định chi nhánh tổ chức } \\
\text { muốn thực hiện ISO }\end{array}$ \\
\hline 2 & Điều khoản 3 & $\begin{array}{l}\text { Thuật ngũ̃ và } \\
\text { định nghĩa }\end{array}$ & $\begin{array}{l}\text { Diễn giải các thuật ngữ và định nghĩa bằng hình thức trình } \\
\text { chiếu, giải thích }\end{array}$ \\
\hline 3 & Điều khoản 4 & $\begin{array}{l}\text { Bối cảnh tổ } \\
\text { chức }\end{array}$ & $\begin{array}{l}\text { Xác định các bên liên quan trong và bên liên quan ngoài của tổ } \\
\text { chức; xác định tồ chức là công ty tư nhân, tập thể, hoặc công ty } \\
\text { đa quốc gia, hoặc các đơn vị sự nghiệp hành chính... }\end{array}$ \\
\hline 4 & Điều khoản 5 & Sự lãnh đạo & $\begin{array}{l}\text { - Xác định bộ máy tổ chức của tổ chức; } \\
\text { - Xác định sự cam kết của lãnh đạo cao nhất } \\
\text { - Xây dựng chính sách môi trường cho tồ chức thông qua đánh } \\
\text { giá đúng lĩnh vực hoạt động, sản phẩm đầu ra và nguồn nguyên } \\
\text { vật liệu đầu vào. }\end{array}$ \\
\hline 5 & Điều khoản 6 & Hoạch định & $\begin{array}{l}\text { - Xác định nguồn đầu vào đầu ra } \\
\text { - Xác định các khía cạnh môi trường và các tác động môi trường } \\
\text { - Xác định các khía cạnh môi trường ý nghĩa ưu tiên giải quyêt } \\
\text { thông qua phương pháp đa tiêu chí } \\
\text { - Hành động giải quyết các rũi ro thông qua phương pháp } 4 \mathrm{~T} \\
\text { - Xác định mục tiêu môi trường và các hoạch định đạt mục tiêu. }\end{array}$ \\
\hline 6 & Điều khoản 7 & Hỗ trợ & $\begin{array}{l}\text { - Xác định nguồn lực của tổ chức } \\
\text { - Xác định năng lực của tồ chức } \\
\text { - Xây dựng nhận thức cho nhân viên } \\
\text { - Trao đồi thông tin về môi trường ở các khía cạnh: chính sách }\end{array}$ \\
\hline
\end{tabular}




\begin{tabular}{|l|l|l|}
\hline & $\begin{array}{l}\text { môi trường; khía cạnh môi trường ý nghĩa; cách khắc phục } \\
\text { phòng ngừa; và mục tiêu chỉ tiêu chương trình }\end{array}$ \\
\hline
\end{tabular}

Nguồn TCVN ISO 14001: 2015 - Hà Nội 2015

Đối với học phần thực hành xây dựng hệ thống quản lý môi trường ISO 14001: 2015 với mức độ hướng dẫn sinh viên cách tiếp cận thực tế nhất, giảng viên chỉ mới triển khai 6/10 điều khoản, và điều đương nhiên là các điều khoản cuối sinh viên sẽ không có cơ hội học thực tế do các đơn vị sinh viên lựa chọn quan sát học tập chủ động, ứng dụng chưa xây dựng hệ thống quản lý môi trường nên việc thực hiện thực tế, đánh giá hiệu quả xây dựng và cải tiến là không thể giảng dạy được. Sinh viên chỉ mới tiến hành ứng dụng thử trên một đơn vị cụ thể dưới dạng bảng nháp.

\subsubsection{Sự chủ động chuẩn bị của sinh viên}

Để chuẩn bị cho học phần thực hành này, sinh viên bắt buộc phải tìm cho được một công ty, xí nghiệp, nhà máy, cơ sở sản xuất, cơ sở kinh doanh, cơ sở dịch vụ, bệnh viện, bến xe, trường học... Bất cứ cơ sở nào sinh viên tiếp cận được, sinh viên hứng thú, thì sinh viên đều có thể thực hiện bài thực hành áp dụng vào thực tế. Điều này sẽ dẫn đến sinh viên phải thực sự chủ động tìm kiếm và lựa chọn tổ chức mà mình muốn trải nghiệm cho học phần.

Phần lớn sinh viên sẽ chọn các nơi sinh viên đang làm thêm, vì các nơi này sinh viên thực sự là nhân viên và có thể dễ dàng ra vào, tiếp cận để học tập... Việc lựa chọn các địa điểm như thế này sẽ phần nào giảm áp lực liên hệ các công ty sản xuất vốn rất nhạy cảm với các sinh viên liên hệ thực tập về môi trường.

Một khía cạnh chất lượng hơn, giảng viên khuyến khích sinh viên tìm kiếm một đơn vị mà sinh viên thích thú, những đơn vị do gia đình hoặc bản thân sinh viên quen biết và có thể xin vào thực tập tốt nghiệp sau này... ở những trường hợp này sinh viên thực sự dễ dàng ra vào tiếp cận các khu vực hoạt động, các quy trình... Đây là các bài tập thực hành thực sự chất lượng, và giảng viên khuyến khích sinh viên mở rộng dùng bài thực hành này nâng cao sau này và phát triển nó thành bài báo cáo tốt nghiệp ra trường.

\subsubsection{Hoạt động học tập chủ động và trải nghiệm của sinh viên}

Sinh viên sẽ có thời gian ra vào công ty và chủ động quan sát các vấn đề như:

- Quan sát các khu vực trong công ty

- Các hoạt động trong các khu vực

- Các quy trình trong các hoạt động,

- Các nguồn vật chất đầu vào và đầu ra

- Các khía cạnh môi trường tác động đến môi trường

- Các yêu cầu luật định mà đơn vị có liên quan đến

- Các giải pháp có thể khắc phục khía cạnh môi trường...

Việc quan sát này thật sự kín đáo và có kế hoạch từng bước, từng khu nhằm tranh thủ nhiều nhất thời gian được phép ra vào tiếp cận các khu vực. Trong suốt thời gian này, sinh viên sẽ liên hệ với giảng viên giảng dạy để điều chỉnh những khu vực, những hoạt động và lựa chọn các hoạt động phù hợp với sinh viên nhất với những khía cạnh môi trường ý nghĩa nhất.

\subsubsection{Sụ giám sát đánh giá của giảng viên}


- Giảng viên với vai trò là người điều phối, người định hướng tổng quát mà không can thiệp vào sở thích, vào lựa chọn của sinh viên. Đảm bảo cho sinh viên có nhiều sự lựa chọn và nhiều quyết định độc lập nhất.

- Giảng viên sẽ chấm tiến độ thực hiện bài của sinh viên,

- Giảng viên sẽ đưa ra rubric định hướng bài tập thực hành cho sinh viên, và rubric này sẽ dùng để chấm điểm thực hiện của sinh viên.

- Giảng viên là người giải đáp các thắc mắc của sinh viên, hướng dẫn sinh viên cách thức tốt nhất để hoàn thành bài thực hành của mình.

\subsection{Những thuận lọii và khó khăn}

\subsubsection{Thuận lợi}

Có rất nhiều thuận lợi trong việc áp dụng học tập chủ động và trải nghiệm cho sinh viên.

- Sinh viên chủ động lựa chọn nơi vận dụng bài học lý thuyết vào để thực hành.

- Khuyến khích sinh viên giao tiếp, tìm kiếm các nơi tiếp nhận.

- Việc chủ động lựa chọn, tìm kiếm nơi thực hành sẽ làm tăng tính hứng thú cho sinh viên.

- Nhà trường không cần xây dựng cơ sở vật chất cho các học phần thực hành kiểu này, nhà trường tận dụng các đơn vị hiện hữu làm nơi cho sinh viên cọ sát, học hỏi.

- Việc cọ sát với các đơn vị thực tế sẽ giúp sinh viên gia tăng tính bản lĩnh, trưởng thành và mạnh dạn hơn nếu sau này bắt gặp mô hình nào đó tương tự

- Thời gian học tập linh động với sự thỏa thuận của sinh viên và đơn vị tiếp nhận, hoặc đối với các đơn vị kinh doanh dịch vụ thì sinh viên càng tự chủ thời gian hơn.

- Sinh viên sẽ tương tác nhiều hơn với giảng viên, nhằm làm rõ các vấn đề và định hướng kịp thời các vấn đề trong lúc làm bài tại đơn vị.

- Đối với các đơn vị quy mô mà sinh viên được phép tiếp cận sâu, sinh viên có điều kiện thực hiện sớm bài báo cáo tốt nghiệp của mình dựa trên sự khuyến khích của giảng viên.

\subsubsection{Khó khăn}

Bên cạnh các thuận lợi, thì sẽ có những khó khăn, trở ngại nhất định

- Sinh viên nếu không chủ động, sẽ khó bắt kịp tiến độ làm bài, từ đó sẽ khó hoàn thành bài thực hành.

- Sinh viên thụ động, ngại giao tiếp thì đây là một thách thức ở khía cạnh tương tác

- Giảng viên phần nào khó nắm bắt hết các nhóm làm bài nếu số nhóm đông và các nhóm ít tương tác với giảng viên.

- Một vài trường hợp không trung thực trong làm bài, không thực sự tiếp cận nơi thực hành. 
- Giảng viên khó quan sát hết các thành viên trong nhóm, sẽ có các thành viên làm nhiều và sẽ có các thành viên ít tương tác đóng góp với nhóm nếu đây là bài tập làm nhóm.

\section{Kết quả}

Trong ba năm học vừa qua, việc áp dụng học tập chủ động và trải nghiệm cho học phần tiêu chuẩn quốc tế ISO phần nào giúp sinh viên hứng thú hơn với môn học, sinh viên có không gian khác ngoài lớp học và sinh viên được tìm tòi các đơn vị mà mình yêu thích. Việc áp dụng học tập chủ động và trải nghiệm cũng giúp cho nhà trường phần nào không cần đầu tư cơ sở vật chất cho học phần này, mà tận dụng cơ sở vật chất của các doanh nghiệp bên ngoài. Điều này vừa có lợi cho nhà trường, có lợi cho sinh viên và cũng có lợi cho doanh nghiệp, vì sau khi ra trường sinh viên phần nào sẽ bớt bỡ ngỡ với môi trường làm việc của công ty.

Tiêu chuẩn quốc tế ISO 14001 thực sự là một thách thức lớn đối với sinh viên ngành môi trường, vì đây cũng là lĩnh vực công việc mới, đòi hỏi sinh viên phải khá giỏi trong việc tương tác, quan sát, phân tích, tổng hợp và lập kế hoạch. Mặt khác theo hướng làm việc này, sinh viên sẽ có mức lương cao hơn bên cạnh trong môi trường làm việc chủ động, hiện đại... song đây cũng là thách thức khả năng ngoại ngữ của sinh viên.

\section{4. Đúc kết những nghiên cứu}

Trong những năm tới, việc triển khai học tập chủ động và trải nghiệm là xu thế chính của nhà trường nói riêng và của các trường đại học khác trong khu vực nói chung. Việc tọa lạc tại tam giác kinh tế miền Đông Nam Bộ, là trường đại học công lập thuộc tỉnh Bình Dương với 28 khu công nghiệp là cơ sở để nhà trường tăng cường triển khai học tập chủ động và trải nghiệm cho sinh viên. Với các điều kiện thuận lợi này, việc làm theo đề xướng CDIO và triển khai giảng dạy học tập chủ động và trải nghiệm tại trường sẽ dễ dàng và nhiều lợi thế.

\section{Tài liệu tham khảo}

[1] Hồ Tấn Nhựt. Đoàn Thị Minh Trinh., "Cải cách và xây dựng chương trình đào tạo kỹ thuật theo phương pháp tiếp cận CDIO”, Nhà xuất bản Đại học Quốc gia Thành Phố Hồ Chí Minh,

[2] Đoàn Thị Minh Trinh. Nguyễn Hội Nghĩa., "Hướng dẫn thiết kế và phát triển chương trình đào tạo đáp ứng chuẩn đầu ra”, Nhà xuất bản Đại học Quốc Gia Tp.HCM, 2014.

[3] Kỷ yếu Hội nghị CDIO toàn quốc., "Đào tạo đáp ứng nhu cầu xã hội và hội nhập quốc tế", Đại Học Quốc Gia Thành Phố Hồ Chí Minh, 2012.

[4] Kỷ yếu hội thảo cấp Khoa., "Chương trình đào tạo và chuẩn đầu ra CDIO đáp ứng nhu cầu xã hội ngành tài nguyên môi trường”, 2014.

[5] Tiêu Chuẩn Việt Nam 14001:2015, Bộ Khoa học và Kỹ Thuật, Hà Nội 2015

[6] Luật Bảo vệ môi trường, Quốc Hội 2013. 